\title{
Synthesis, Characterization and Bioactivity Profiling of Gold Nanoparticles of Trachyspermum ammi Crude Extract
}

\author{
Saud Bawazeer ${ }^{1}$, Abdur Rauf'* (D), Humaira Naz ${ }^{3}$, Syed Uzair Ali Shah", \\ Dania Saad Waggas ${ }^{5}$, Jawad Ali ${ }^{2}$, Yahia N. Mabkhot ${ }^{6}$, Faryal ${ }^{7}$ and \\ Mohamed Fawzy Ramadan ${ }^{8}$ (D) \\ ${ }^{1}$ Department of Pharmaceutical Chemistry, Faculty of Pharmacy, Umm Al-Qura University, \\ Makkah, P.O. Box 42, Saudi Arabia. \\ ${ }^{2}$ Department of Chemistry, University of Swabi, Swabi, Anbar, KP, Pakistan. \\ ${ }^{3}$ Department of Zoology, Shaheed Benazir Bhutto Women University Peshawar, KP, Pakistan. \\ ${ }^{4}$ Department of Pharmacy, University of Swabi, Swabi, KP, Pakistan. \\ ${ }^{5}$ Pharmacology, Fakeeh College for Medical Sciences, Jeddah, Saudia Arabia. \\ ${ }^{6}$ Department of Pharmaceutical Chemistry, College of Pharmacy, King Khalid University, Abha 61421, Saudi Arabia. \\ ${ }^{7}$ Institute of Chemical Sciences, University of Peshawar, KP, Pakistan. \\ ${ }^{8}$ Biochemistry Department, Faculty of Agriculture, Zagazig University, Zagazig 44519, Zagazig, Egypt.
}

\begin{abstract}
Trachyspermum ammi seeds were selected for photochemical study. The crude $T$. ammi methanol and aqueous extracts showed the presence of alkaloids, saponins, steroids, terpenoids, coumarins, betacyanins, flavonoids and soluble starch. The synthesis of gold nanoparticles (AuNPs) using T. ammi extract was characterized using UV-visible, and FT-IR spectroscopy. The appearance of sharp peak at $520 \mathrm{~nm}$ in the UV visible spectra, and the appearance of broad band nanoparticles spectra at 563.21 $\mathrm{cm}^{-1}, 516.92 \mathrm{~cm}^{-1}$ and $462.92 \mathrm{~cm}^{-1}$ as well as the disappearance of the carboxyl OH bond and carboncarbon triple bond supported the formation of AuNPs. The crude T. ammi methanol and AuNPs were investigated for antioxidant potential using DPPH - free radical assay, which shows that crude extract has significant antioxidant effect. The synthesized AuNPs was also evaluated for antibacterial activities against staphylococcus aureus, Klebsiella pneumonia and Bacillus subtilis. The crude extract showed activity against Bacillus subtilis, while AuNPs showed activity against staphylococcus aureus. The in vivo sedative effect and analgesic effect were enhanced in AuNPs treated animals in 5 times less dose (i.e., 5 , and $10 \mathrm{mg} / \mathrm{kg}$ ) than that of crude extract. It was concluded that $T$. ammi extract includes capping and reducing agents, which make it capable to be developed as stable AuNPs. The biological action of AuNPs is either enhanced (sedative and analgesic) or changed (antibacterial activity), when compared with that of plant extract.
\end{abstract}

Keywords: Nanotechnology, phytochemicals, biological activities, sedative effect, analgesic effect

*Correspondence: mashaljcs@yahoo.com; (Received: December 18, 2020; accepted: March 30, 2021)

Citation: Bawazeer S, Rauf A, Naz H, et al. Synthesis, Characterization and Bioactivity Profiling of Gold Nanoparticles of Trachyspermum ammi Crude Extract. J Pure Appl Microbiol. 2021;15(2):667-676. doi: 10.22207/JPAM.15.2.11

(c) The Author(s) 2021. Open Access. This article is distributed under the terms of the Creative Commons Attribution 4.0 International License which permits unrestricted use, sharing, distribution, and reproduction in any medium, provided you give appropriate credit to the original author(s) and the source, provide a link to the Creative Commons license, and indicate if changes were made. 


\section{INTRODUCTION}

The medicinal plants provided the ailments and cure throughout human history. Medicinal plants are e capable of making various ranges of secondary metabolites which possess diverse biological potentials ${ }^{1}$. Even at dawn of $21^{\text {st }}$ century, about $90 \%$ of probable novel drug molecules have been purified directly or indirectly ${ }^{2}$. As per WHO report about $80 \%$ of the people of some Africo-Asian countries nowadays, use herbal medicine for some aspect of primary health care ${ }^{3}$. The clinical application of herbal drugs faces the same challenges as allopathic medicines like effectiveness, drug delivery, safety, selectivity, solubility, toxicity and frequent dosing ${ }^{4,5}$. The modern pharmaceutical research could overcome the abovementioned challenges by adopting novel drug delivery techniques for herbal medicines, such as development of matrix system, micro emulsion, solid dispersion, liposomes and solid lipid NPs, nanoparticles (NPs) ${ }^{6,7}$.

The field of nanotechnology has grown widely in past few decades with efficient applications in biomedical sciences, food processing, and pharmacology $y^{8-10}$. It deals with matter at the scale of one billionth of a meter, so the NPs is the most fundamental component in the fabrication of a nanostructure. The nano-size atoms and molecules exhibit different properties, and ultimately show a variety of surprising and interesting results ${ }^{11,12}$. There are various methods reported for fabrication of NPs, but metal NPs like gold and silver are extensively studied due to their unique electrical and optical properties. Gold nanoparticles (AuNPs) are increasingly studied because of their wide applications in antibacterial agents, detectors, and sensors ${ }^{13-15}$. In old Indian medical system (Ayurveda), gold salt was used as medicine in the preparations to treat anemia, tuberculosis, and cough. In traditional medicines, the gold has been explored for various disease ailment and shown with efficient antibacterial and antifungal properties ${ }^{16-19}$.

Trachyspermum ammi is an annual herbal plant belongs to family Apiaceae, indigenous to Egypt but cultivated in Iran, Pakistan and India and Europe. It is commonly known as Ajwain in India. The green seeds as well as fruits $T$. ammi are well recognized for medical and nutritional purposes ${ }^{20}$. The structural composition of T. ammi include proteins (17.1\%), fats (21.1\%), glycosides $(12 \%)$, carbohydrates, saponins, flavones and other components (7.1\%) involving copper, calcium, cobalt, iron, iodine, manganese, nicotinic acid, phosphorous, riboflavin, and thiamine. The T. ammi is known for its brownish essential oil (5\%) that responsible for its odor and taste ${ }^{21}$. The plant has medical application in Medieval and Traditional Persian Medicine for paralysis, tremor and palsy as well as other disorders in the field of neurology. The plant used for the auditory and olfactory weakness and infections $\mathrm{s}^{20,21}$. The T. ammi was beneficial in cough, Pleurisy and dysphonia, anthelmintic, gastrointestinal disorders and have carminative properties. The Persian practitioner considered the seeds as a diuretic agent and beneficial for dissolving the stones when used with wine ${ }^{22}$.

In the present study, we aimed to synthesize the AuNPs of $T$. ammi methanol and aqueous extract keeping in view its extensive medical applications. The synthesized AuNPs were characterized and analyzed for its stability. The newly synthesized AuNPs were biologically screened analgesic, sedative and antibacterial effects and compared with respective therapeutic effect of the crude T. ammi extract.

\section{MATERIALS AND METHODS}

\section{Chemicals and plant sampling}

Gold chloride, potassium bromide, 1,1-diphenyl-2-picrylhydrazyl (DPPH·), methanol, sulphuric acid, and trichloro methane were from Sigma (St. Louis, MO, USA). Trachyspermum ammi was procured from local market (Peshawar, Pakistan). The plant was identified by taxonomist Ghulam Jilani from Botany Department, University of Peshawar, Pakistan.

\section{Extraction of $T$. ammi seeds}

To prepare the extract, $500 \mathrm{~g}$ of $T$. ammi seeds were dipped in distilled water and methanol using conical flask, respectively and kept in water bath. The two solutions, obtained after three days, were filtered and the filtrates were concentrated in rotary evaporator. Further evaporation was allowed in water bath for two days to procure water and methanol solid extract ${ }^{21,22}$.

\section{Phytochemicals profiling}

Tests for phytochemicals like tannins, anthraquinones, alkaloids, saponins, glycosides, 
reducing sugars, flavonoids, steroids, terpenoids, phlobatanins, anthocyanins, betacyanins, cardiac glycosides, emodins, coumarins and free reducing sugars were carried out ${ }^{20-22}$.

\section{Synthesis of AuNPs}

\section{Preparation of stock and gold salt solution}

The extract stock solution was prepared by dissolving $1 \mathrm{~g}$ of solid extracts of $T$. ammi (methanolic and aqueous) in $100 \mathrm{~mL}$ methanol and/or water. Another stock solution of gold salt was prepared by adding $34 \mathrm{mg}$ of gold chloride to $100 \mathrm{~mL}$ of methanol solution ${ }^{18}$.

\section{Formation of AuNPs}

Four samples of $5 \mathrm{~mL}$ stock solution of water and methanol extracts were added to the $5 \mathrm{~mL}, 10 \mathrm{~mL}, 15 \mathrm{~mL}$, and $20 \mathrm{~mL}$ gold salts solution separately, stirred on hot stirring plates on 40 to $60^{\circ} \mathrm{C}$ for $60 \mathrm{~min}$ and observed its UV spectrum for confirmation of synthesis of AuNPs ${ }^{18}$.

\section{Characterization of AuNPs \\ UV visible spectroscopy}

UV visible spectra was recorded at room temperature to monitor the formation and stability of AuNPs. The wave length $(\Lambda)$ were fixed between $300 \mathrm{~nm}$ and $700 \mathrm{~nm}$ and the base line was drawn by the methanol solution. The peak in the 500-600 $\mathrm{nm}$ range indicates the presence of AuNPs ${ }^{23}$.

\section{FTIR Spectroscopy}

An FTIR spectrum was recorded and the measurement was performed to recognize the possible functional groups of molecules responsible for capping and effective stabilization of the nanoparticles synthesized ${ }^{18}$.

Biological evaluation of crude extract and AuNPs

The crude extract and synthesized AuNPs were evaluated in vitro and in vivo for various biological activities.

\section{In vitro biological activities}

\section{Antibacterial activity}

Antibacterial activity was performed by disk diffusion technique. The procedure was done in laminar airflow, Forceps, Petri dish, cotton swab, disc sterilized and utilized for plating. Sterile environment was maintained by HEPA (high performance efficient particle air) in the laminar flow. A few colonies of the organism are inoculated in $5 \mathrm{~mL}$ broth and cultured for $2 \mathrm{~h}$. The cultures were diluted to a density of the $1 \%$ barium sulfate standard. After $15 \mathrm{~min}$ bacterial cultures were spread on agar surface by spread plating method. When the inoculum dried, the impregnated discs were spread on the agar surface with flamed forceps and pressed down to ensure contact. The discs were sterilized by autoclaving and then dried at $80^{\circ} \mathrm{C}$ for at least $1 \mathrm{~h}$. The sterile discs were immersed in extract solution $(2 \mathrm{mg} /$ $\mathrm{mL})$, and AuNPs solution ( $1 \mathrm{mg} / \mathrm{mL}$ ) then placed on Petri plates. The impregnated discs are dried for $5 \mathrm{~min}$ and washed with water. The discs dried at $25^{\circ} \mathrm{C}$ for $15 \mathrm{~min}$ were pressed down to make certain complete contact of the disc with the agar surface. Ampicillin was used as positive control for antibacterial screening test. The discs were spread out far sufficient to stop both reflection waves from the preparation of methanolic extract edges of the Petri plates and overlapping rings of inhibition. The plates were incubated at $37^{\circ} \mathrm{C}$ for $12 \mathrm{~h}$. The diameter of the zone of inhibition was determined $^{19}$.

\section{Antioxidant activity}

The stock solution of crude extract was organized by dissolving $25 \mathrm{mg}$ in $50 \mathrm{~mL}$ methanol. For antioxidant activity, different concentrations were prepared from stock solution by diluting with methanol (i.e., 20, 40, 60, 80, 100 and $150 \mu \mathrm{g} / \mathrm{mL}$ ). Similar concentrations were prepared for AuNPs. One $\mathrm{mL}$ of DPPH. was added to each of PPM concentration and the solution was placed in the darkness for $30 \mathrm{~min}$ and then UV-visible spectra was measured at $515 \mathrm{~nm}$. Antioxidant activity of both crude and nanoparticles base line is made on a solution of $4 \mathrm{~mL}$ methanol and $1 \mathrm{~mL} \mathrm{DPPH}$. and it's percent activity is calculated by the following formula ${ }^{24}$ :

Percent $(\%)$ activity = control-absorbance/ control $* 100$

\section{In vivo biological activities}

Animals

In this experiment BALB/C mice were used. Mice were kept under standard light/dark cycles and temperature with standard supply of food (normal laboratory food and water adlibitum). Prior to the experiment, mice were familiarized with laboratory conditions. The rulings of the institutes of Laboratory Animal Resources, Commission on Life Sciences, National Research Council were maintained during whole course of study. The protocols of all experiments 
were approved by the ethical committee of the Department of Pharmacy, University of Peshawar, Pakistan.

\section{Acute toxicity testing}

The acute toxicity screening was done as per reported procedure of Khan et al. Animals were divided into various groups $(n=6)$. The extract of T. ammi was screened at 50, 100, 200, 300, 400, $500 \mathrm{mg} / \mathrm{kg}$ (body weight of mice). The AuNPs of T. ammi was screened at $1,5,10,20,30,40 \mathrm{mg} /$ $\mathrm{kg}$ (body weight mice). After administration (i.p.) of the above-mentioned test doses, the animals were observed for $24 \mathrm{~h}$ duration. The mortality and survival ratio was noted and percent mortality was calculated $^{25}$.

\section{Sedative activity}

The design of the device for sedative activity covers an area of whitish woody structure possessing a diameter of $1500 \mathrm{~mm}$. The stainless steel was used for fencing and the structure was partitioned into 19 square boxes. Open field of the structure was positioned in a room with ample space. Balb-C mice ( $n=6)$ weighing $26 \pm 4$ g were used. The mice were familiarized with light of red color by keeping them under a 40 Watt red bulb for $1 \mathrm{~h}$ prior to start of the experiment. The normal control animals were injected distilled water as blank $(10 \mathrm{~mL} / \mathrm{kg})$. The reference group was treated with $0.5 \mathrm{mg} / \mathrm{kg}$ diazepam. The rest of the groups were treated with crude extract $(50$, and $100 \mathrm{mg} /$ kg, i.p.) and AuNPs (5 and $10 \mathrm{mg} / \mathrm{kg}$, i.p). After a time interval of $30 \mathrm{~min}$, all mice were placed one by one in the middle of box, and the number of lines passed by each animal was noted ${ }^{25}$.

Acetic acid induced writhing test

Peripheral nociceptive action of T. ammi extracts along with synthesized AuNPs was examined by applying the acetic acid-induced writhing test ${ }^{25}$. The pre-screened mice were distributed in 6 groups where each group contained six animals. The pain was triggered by injecting $0.9 \%$ acetic acid (v/v, $0.1 \mathrm{~mL} / 10 \mathrm{~g}$ body weight) intraperitoneally. The control group (six animals) was given normal saline $(10 \mathrm{~mL} / \mathrm{kg}$, i.p.), whereas second group was provided with diclofenac sodium (10 mg/kg i.p.) as a standard drug. The remaining groups received Trachyspermum ammi extract (50 and $100 \mathrm{mg} / \mathrm{kg}$ i.p) and synthesized AuNPs (5 and $10 \mathrm{mg} / \mathrm{kg}$ i.p). After the injection of $0.9 \%$ acetic acid, the total numbers of contractions in muscles were recorded for 20 minutes each group and compared to that of control group (saline treated group).

\section{Statistical analysis}

All of the results are presented as mean \pm S.E.M and One-way ANOVA was applied in order to compare significant variances among groups followed by Dunnet's multiple comparison post-test. The significance level ( $p<0.05$ or 0.01 ) was considered valid in the study. The results of antibacterial and antioxidant activities are also given as mean \pm SEM of three readings and their statistical analysis were carried out using the GraphPad program.

\section{RESULTS AND DISCUSSION \\ Phytochemical screening}

The analysis of T. ammi aqueous and methanol extract exhibited the presence of various phytochemicals (Table 1). The aqueous extract of T. ammi showed positive result for the presence of alkaloids, flavonoids, terpenoids, and saponins. Methanol crude extract showed positive results for the presence of flavonoids, betacynins, terpenoids, and steroids. This preliminary phytochemical

Table 1. Phytochemical assortment of Trachyspermum ammi extracts

\begin{tabular}{lcc}
\hline $\begin{array}{l}\text { Chemical } \\
\text { components }\end{array}$ & $\begin{array}{c}\text { Aqueous } \\
\text { extract }\end{array}$ & $\begin{array}{c}\text { Methanol } \\
\text { extract }\end{array}$ \\
\hline Alkaloids & + & - \\
Tannins & - & - \\
Anthraquinones & - & - \\
Glycosides & - & - \\
Reducing Sugars & - & - \\
Saponins & + & - \\
Flavonoids & + & + \\
Phlobatannins & - & - \\
Steroids & - & + \\
Terpenoids & + & + \\
Cardiac glycosides & - & - \\
Coumarin & - & + \\
Emodins & - & - \\
Betacyanins & - & + \\
Carbohydrates & - & - \\
Monosaccharides & - & - \\
Free reducing sugars & - & - \\
Combined reducing sugars & - & - \\
Starch & - & - \\
& &
\end{tabular}


screening made it clear that the both extracts have various phytochemicals which would act as both capping and reducing agents for the synthesis of $\mathrm{NPs}^{20-22}$.

\section{Characterization of AuNPs \\ UV-visible spectroscopy}

The production of AuNPs is generally detected by UV-Vis spectroscopy which specifically measures surface plasmon resonance peaks of AuNPs. The noble metals exhibited distinctive optical properties due to the property of surface plasmon resonance. When $T$. ammi extract was added to salt solution at $40-60^{\circ} \mathrm{C}$ temperature, the solutions changed from yellow to brown, indicating the formation of AuNPs. The color of the solution was changed because of reduction of gold $\left(\mathrm{Au}^{3+}\right.$ to $\left.\mathrm{Au}^{0}\right)$ by the active phytochemicals present in $T$. ammi extract ${ }^{26}$. Previously reported studies showed that phytochemicals act as capping and reducing agents. The variety of constituents in the natural extracts leading to the synthesis of symmetrical NPs ${ }^{27}$. Experiment was carried out with varying stock solutions of $T$. ammi extract and salt concentrations. In order to monitor the formation and stability of AuNPs, the absorption spectra of the synthesized AuNPs were recorded against methanol. The peak absorbance of AuNPs was observed in wavelength $(\Lambda)$ range of 500-600 $\mathrm{nm}$ in methanol solutions, which exhibited the successful formation of AuNPs.

FTIR spectra analysis of crude extract and AuNPs The FTIR spectra acquired from the crude extract of $T$. ammi and synthesized AuNPs are demonstrated in Fig. 2 and 3. In Fig. 2, The $\mathrm{O}-\mathrm{H}$ bonds stretching is attributed by a broader peak observed at $3392 \mathrm{~cm}^{-1}$, evidenced the presence of aromatic alcoholic and phenolic compounds. The peaks such as $2947.23 \mathrm{~cm}^{-1}, 2831.50 \mathrm{~cm}^{-1}, 2592.33$ $\mathrm{cm}^{-1}$, and $2522.89 \mathrm{~cm}^{-1}$ reflect carboxylic acid bond

Table 2. DPPH• free radical scavenging activities of $T$. ammi crude extract and AuNPs

\begin{tabular}{lcc}
\hline & \multicolumn{2}{c}{ Percent activity (\%) } \\
\cline { 2 - 3 } $\begin{array}{l}\text { Concen. } \\
(\mu \mathrm{g} / \mathrm{mL})\end{array}$ & $\begin{array}{c}\text { Methanol } \\
\text { extract }\end{array}$ & AuNPs \\
\hline 20 & 44.79 & 36.40 \\
40 & 58.91 & 46.97 \\
60 & 64.51 & 54.56 \\
80 & 76.34 & 60.16 \\
100 & 82.17 & 61.60 \\
150 & 84.22 & 63.59
\end{tabular}

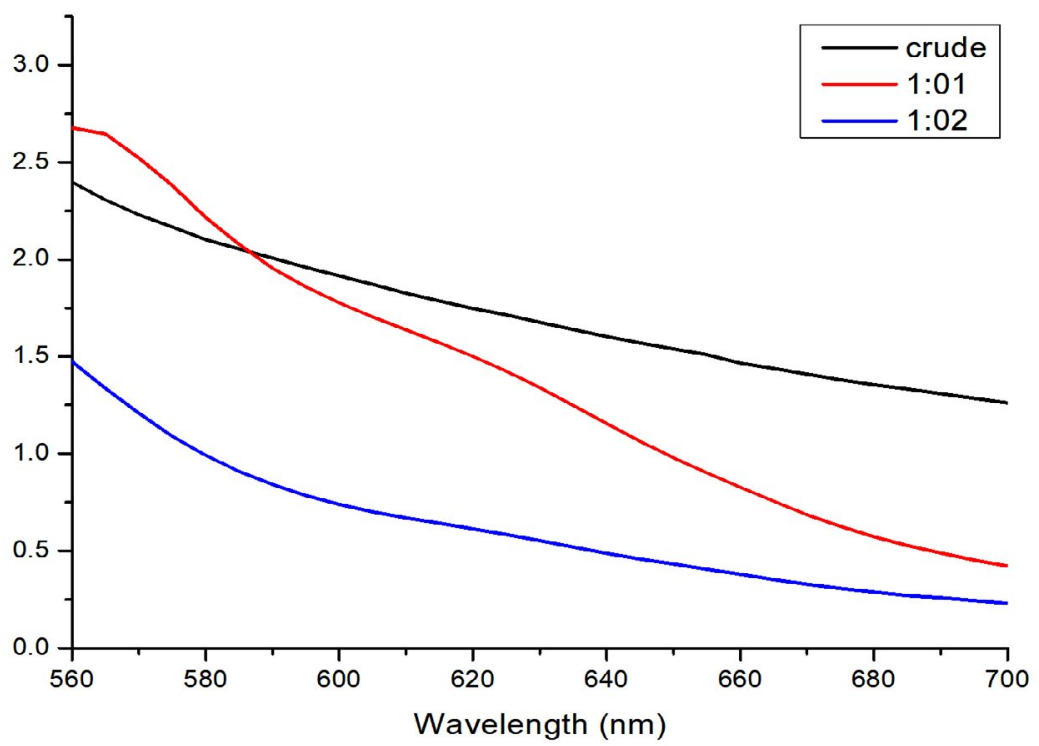

Fig. 1. UV-visible spectra of T. ammi extract solution and synthesized AuNPs Where,

Crude: extract solution of T. ammi,

1:01: showed AuNPs synthesized by mixing stock solution and salt solution (1:1, v/v),

1:02: showed AuNPs synthesized by mixing stock solution and salt solution with $(1: 2, \mathrm{v} / \mathrm{v})$ 
stretching. The peak at $2368.59 \mathrm{~cm}^{-1}, 2222.00 \mathrm{~cm}^{-1}$ and $2044.54 \mathrm{~cm}^{-1}$ show $\mathrm{C} \equiv \mathrm{C}$ stretching. The peak of $1658.78 \mathrm{~cm}^{-1}$ shows carbonyl group and peak at $1411.89 \mathrm{~cm}^{-1}$ shows C-C stretching. The peak at $1211.30 \mathrm{~cm}^{-1}$ shows $\mathrm{C}-\mathrm{N}$ stretching and peak at $1026.13 \mathrm{~cm}^{-1}$ shows $\mathrm{C}-\mathrm{H}$ single bond stretching. The peak at $655.80 \mathrm{~cm}^{-1}$ shows $\mathrm{C}-\mathrm{Br}$ stretching.

When this FTIR spectra was compared with that of AuNPs, the spectra exhibited different IR absorption. The FTIR spectra acquired for AuNPs after 1 hour of reaction for observing the involved functional groups present in T. ammi extract (Fig. 3). The peaks at $2592.33 \mathrm{~cm}^{-1}, 2522.89 \mathrm{~cm}^{-1}$, $2368.59 \mathrm{~cm}^{-1}$ and $2222.00 \mathrm{~cm}^{-1}$ disappear in the spectra of FTIR spectra of AuNPs. Thus, it means that carboxyl bond and carbon-carbon triple are considered accountable for reduction and stabilization of AuNPs ${ }^{28}$. Broad bands observed in spectra of AuNPs $563.21 \mathrm{~cm}^{-1}, 515.92 \mathrm{~cm}^{-1}$ and $462.92 \mathrm{~cm}^{-1}$ validated the formation of AuNPs, which were not observed in the crude FTIR Spectrum ${ }^{29}$.

Biological evaluation of crude extract and AuNPs Antioxidant Activity

The free radical scavenging against DPPH. is a simple and commonly used assay for the study of antioxidant potential of tested compounds ${ }^{30-32}$. This is a chromophoric assay in which change in absorbance is indicated by change in color and then measured. The free scavenging effect of crude extract vs synthesized AuNPs is shown in the Table 2. The antioxidant activity of crude extract of $T$. ammi was higher as compared to the AuNPs. As the concentration of the stock solution and AuNPs increases, its antioxidant effect increases. The data demonstrated that the net antioxidant effect of AuNPs decrease as compared to extract.

\section{Antibacterial activity}

To analyze the comparative antibacterial effect of crude extract and AuNPs, they were screened against gram positive and negative bacteria as given in Table 3 . The crude extract as well as synthesized AuNPs were ineffective against Klebsiella pneumonia. The crude extract exhibited sample shows activity for Bacillus subtilis, while AuNPs showed activity for staphylococcus aureus. However in both cases the zone of inhibition $(10 \mathrm{~mm})$ was far less than that of standard ampicillin $(30 \mathrm{~mm})$. The data exhibited that the AuNPs synthesis of $T$. ammi extract changed its antibacterial properties. The thymol isolated from T.ammi is potent antibacterial agent and

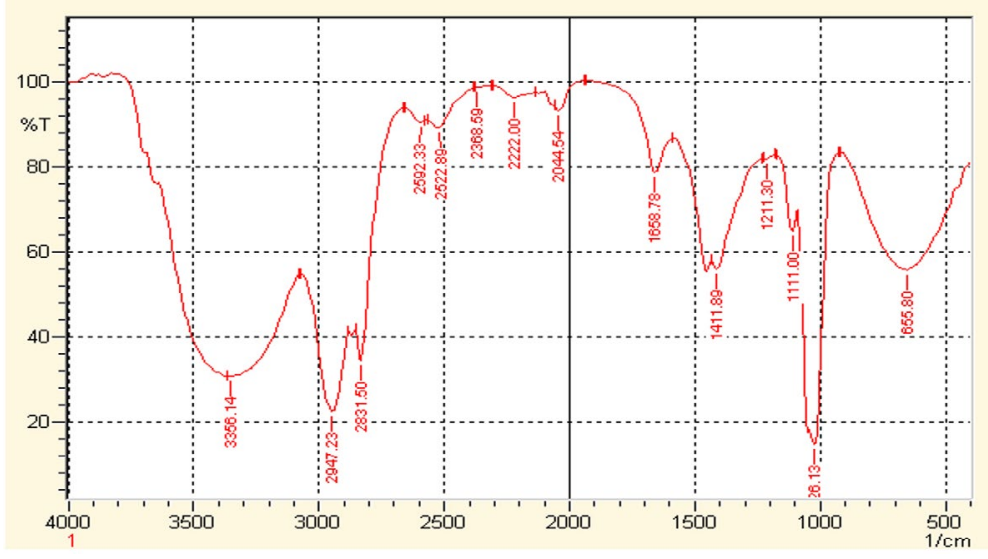

Fig. 2. FTIR spectrum of crude T. ammi extract

Table 3. Antibacterial activity of T. ammi crude extract and AuNPs

\begin{tabular}{|c|c|c|c|c|}
\hline Microorganism & Gram stain & Crude extract & AuNPs & Ampicillin \\
\hline & & Diameter of $z$ & e of inhi & ion (mm) \\
\hline Klebsiella Pneumonia & - & 0 & 0 & 30 \\
\hline Staphylococcus aureus & + & 0 & 10 & 30 \\
\hline Bacillus subtilis & + & 10 & 0 & 30 \\
\hline
\end{tabular}


Table 4. Sedative activity of Trachyspermum ammi extract and AuNPs

\begin{tabular}{lcc}
\hline Treatment & $\begin{array}{c}\text { Dose } \\
(\mathrm{mg} / \mathrm{kg})\end{array}$ & $\begin{array}{c}\text { No. of lines } \\
\text { crossed in } 10 \mathrm{~min}\end{array}$ \\
\hline Distilled water & 10 & $125 \pm 1.15$ \\
Diazepam & 0.5 & $6 \pm 0.14$ \\
Extract & 50 & $122.4 \pm 2.70$ \\
& 100 & $113.4 \pm 2.42$ \\
AuNPs nanoparticles & 5 & $96.56 \pm 0.84$ \\
& 10 & $82.40 \pm 1.78$ \\
\hline
\end{tabular}

Table 5. Analgesic activity of Trachyspermum ammi extract and AuNPs

\begin{tabular}{lcc}
\hline Treatment & $\begin{array}{c}\text { Dose } \\
(\mathrm{mg} / \mathrm{kg})\end{array}$ & $\begin{array}{c}\text { No. of lines } \\
\text { crossed in } 10 \mathrm{~min}\end{array}$ \\
\hline Normal saline & $10(\mathrm{~mL} / \mathrm{kg})$ & $65.4 \pm 3.48$ \\
Diclofenac sodium & 1 & $17.6 \pm 1.38$ \\
Extract & 50 & $52.3 \pm 2.44$ \\
& 100 & $30.2 \pm 2.13$ \\
AuNPs & 5 & $48.2 \pm 2.00$ \\
& 10 & $26.3 \pm 1.67$ \\
\hline
\end{tabular}

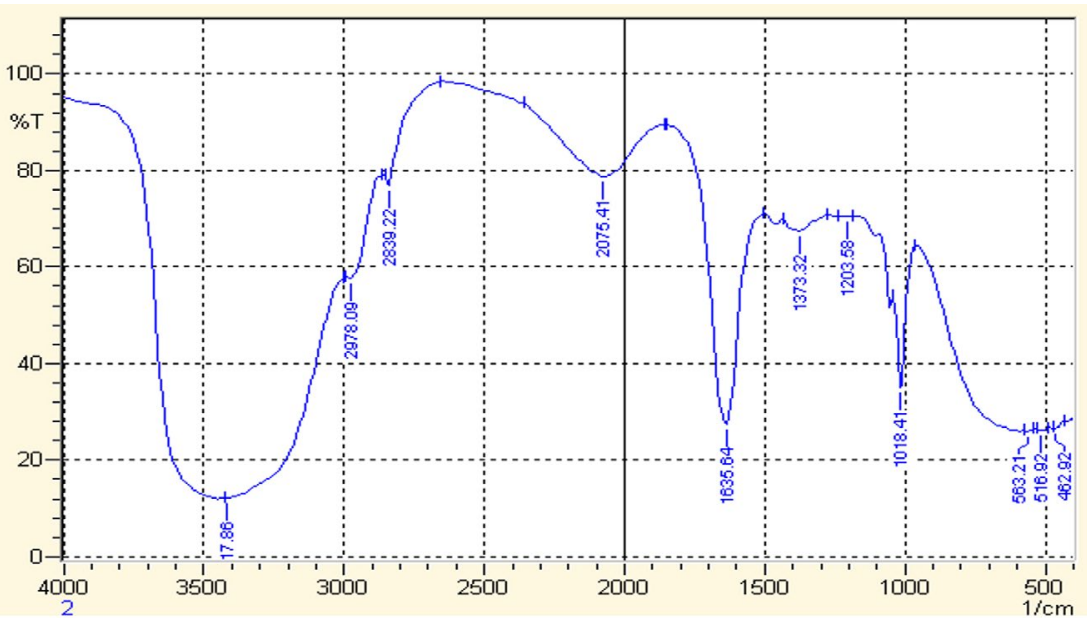

Fig. 3. FTIR spectrum of AuNPs synthesized by mixing extract stock solution and salt solution $(1: 2, \mathrm{v} / \mathrm{v})$

considered to disrupt bacterial membrane function $^{34}$

\section{Acute toxicity dose determination}

The acute toxicity of $T$. ammi crude extract was assessed in dose of 50,100, 200, 300,400 , and $500 \mathrm{mg} / \mathrm{kg}$. Whereas the AuNPs was screened at doses of $1,5,10,20,30$, and 40 $\mathrm{mg} / \mathrm{kg}$. The animals exhibited behavioral toxicity, no mortality during $24 \mathrm{~h}$ of assessment. For the comparison of in vivo effect assessment between extract and AuNPs, extract dose used was 50, and $100 \mathrm{mg} / \mathrm{kg}$, however, AuNPs dose used was 5 -times less than that of extract (i.e., 5 and $10 \mathrm{mg}$ / $\mathrm{kg}$ ).

\section{Sedative activity}

The sedative effect of natural products is frequently assessed by application of open field assay in experimental animals ${ }^{33}$. By comparing the treated (with extract and AuNPs) groups with diazepam-treated group, it was found that T. ammi has very high potential for sedation. Pretreatment of mice with $T$. ammi crude extract $(50 \mathrm{mg} / \mathrm{kg}$ ) showed locomotory activity comparable to normal animal, however, slight decrease was observed at dose of $100 \mathrm{mg} / \mathrm{kg}$. Pretreatment of mice with AuNPs (5, and $10 \mathrm{mg} / \mathrm{kg}$ ) showed locomotory activity comparable with that of high doses of extract (50, and $100 \mathrm{mg} / \mathrm{kg})$. The data showed that the effect of AuNPs enhanced compared to T. ammi extract. The sedative potential of T. ammi has already been explored ${ }^{34}$. Various compounds have tendency to change neurological behavior ${ }^{35}$. The monoterpene (thymol) isolated from T. ammi is evaluated as allosteric modulator of GABAA receptor ${ }^{36}$. The same GABA receptor is the site of action for reference drug diazepam thereby increasing the chloride influx and causes neuronal hyperpolarization.

\section{Analgesic activity}

Various methods are applied for analyzing the peripheral or central analgesic potential of plant extracts and drugs. One of most preferred 
method for assessment of peripheral analgesia is the acetic acid induced pain model, due to its sensitivity, rapid execution ${ }^{37}$. The method is based on the principle of analyzing abdominal writhes (constriction) produced by inflammatory markers after acetic acid injection. The substances producing inhibition of writhing may associate with decline production or inhibition of inflammatory markers, such as prostaglandins, prostacyclins, in the decreased production or inhibition of proteinoids, at peripheral level ${ }^{38,39}$. The substances capable of inhibition of receptors for the inflammatory markers could exhibit the peripheral analgesic effect. The analgesic effect of active constituents present in samples under analysis is measured in terms of inhibition of acetic acid induced abdominal constrictions (writhing). Therefore, we evaluated the analgesic potential of extract and AuNPs by using acetic acid induced writhing test. Our data showed that $T$. ammi extract in $50 \mathrm{mg} / \mathrm{kg}$ has mild analgesic potential, which increased to moderate effect at dose of $100 \mathrm{mg} / \mathrm{kg}$ compared to reference drug. Slight enhanced analgesic activity was observed in less doses of AuNPs (5 to $10 \mathrm{mg} / \mathrm{kg}$ ). The analgesic and anti-inflammatory potential of $T$. ammi has already been explored in various studies ${ }^{34,40}$. The T. ammi extract contain terpenes, sterols and glycosides, which are suggested to have effect on kinin, bradykinin, prostaglandins and lysozymes synthesis thereby reducing inflammation and allodyna (pain) ${ }^{41,42}$.

\section{CONCLUSION}

The data concluded that the T. ammi extract have necessary capping and reducing agents, which make it capable to be developed as stable AuNPs. The AuNPs showed enhanced biological effect which explain that the pharmacokinetic parameters like bioavailability is increased. The biological action of AuNPs is enhanced in case of antibacterial activity, which means that AuNPs might change the specificity of T. ammi and likewise other drugs.

\section{ACKNOWLEDGMENTS}

The authors extend their appreciation to the Deanship of Scientific Research at King Khalid University for funding this work through Research group Project under grant number (R.G.P. /52/42).
The work is funded by grant number 14-MED33310 from the National Science, Technology and Innovation Plan (MAARIFAH), the King AbdulAziz City for Science and Technology (KACST), Kingdom of Saudi Arabia. We thank the Science and Technology Unit at Umm Al-Qura University for their continued logistic support.

\section{CONFLICT OF INTEREST}

The authors declare that there is no conflict of interest.

\section{AUTHORS' CONTRIBUTION}

SB, AR, HN, SUAS, JA, GU, and F drafted the manuscript, compiled information from the literature, and designed the Fig. and tables. SB, AR, HN, SUAS, JA, GU, and F drafted the manuscript and gathered information from the literature. MFR reviewed the manuscript.

\section{FUNDING}

Deanship of Scientific Research at King Khalid University for funding this work through Research group Project under grant number (R.G.P. /52/42).

\section{DATA AVAILABILITY}

All datasets generated or analyzed during this study are included in the manuscript.

\section{ETHICS STATEMENT}

This article does not contain any studies with human participants or animals performed by any of the authors.

\section{REFERENCES}

1. Daniel AD, Sylvia U, Ute R. A Historical Overview of Natural Products in Drug Discovery. Metabolites. 2012;2(2):303-336. doi: 10.3390/metabo2020303

2. Veeresham C. Natural products derived from plants as a source of drugs. J Adv Pharm Technol Res. 2012;3(4):200-201. doi: 10.4103/2231-4040.104709

3. Fabricant DS, Farnsworth NR. The value of plants used in traditional medicine for drug discovery. Environ Health Persp. 2001;109(1):69-75. doi: 10.1289/ ehp.01109s169

4. Yadev D, Suri S, Choudhary AA, et al. Novel approach, herbal remedies and natural products in pharmaceutical science as nano drug delivery systems. Int J Pharm Tech Res. 2011;3(3):3092-3116.

5. Ratnam DV, Ankola DD, Bhardwaj V, Sahana DK, Kumar MN. Role of antioxidants in prophylaxis and therapy: a pharmaceutical prospective. J Control Release. 
2006;113:189-207. doi: 10.1016/j.jconrel.2006.04.015

6. Miraculous therapeutic effects of herbal drugs using novel drug delivery systems. International Research Journal of Pharmacy. 2012;3:27- 30 .

7. Sharma AT, Mitkare SS, Moon RS. Multicomponent Herbal Therapy: A Review. International Journal of Pharmaceutical Sciences Review and Research. 2011;6:185-187.

8. Rajiv S, Santosh S, Sharma, S. Nanotechnology: the future medicine. J. Cutan. Aesthet. Surg., 2010, 3, (1), pp. 32-33.

9. Bawazeer S, Rauf A, Rahman KU, et al. Green Synthesis and Antimicrobial Potential of Silver/Gold Nanoparticles Functionalized with Debregeasia salicifolia D. Don. J Pure Appl Microbiol. 2020;14(4):2513-2523.

10. Islam NU, Jalil K, Shahid M, Muhammad N, Rauf A. Pistacia integerrima gall extract mediated green synthesis of gold nanoparticles and their biological activities. Arab. J. Chem. 2015;12(8):2310-2319.

11. Raffaele C, Luca ID, Luise AD, Petillo O, Calarco A, Peluso G. New therapeutic potential of nanosized phytomedicine. J Nanosci Nanotechnol. 2016;16(8):8176-8187. doi: 10.1166/jnn.2016.12809

12. Chakraborty K, Shivakumar A, Ramachandran S. Nanotechnology in herbal medicines: A review. International Journal of Herbal Medicine. 2016;4(3):21-27. doi: 10.22271/flora.2016.v4.i3.05

13. Verma HN, Singh P, Chavan RM. Gold nanoparticle: synthesis and characterization. Veterinary World. 2014;7(2):72-77. doi: 10.14202/vetworld.2014.72-77

14. Yazid H, Adnan R, Hamid SA, et al. Synthesis and characterization of gold nanoparticles supported on zinc oxide via the deposition-precipitation method. Turk J Chem. 2010;34:639-650.

15. Daniel MC, Astruc D. Gold nanoparticles: assembly, supramolecular chemistry, quantum-size-related properties, and applications toward biology, catalysis, and nanotechnology. Chem Rev. 2004;104(1):293-346. doi: $10.1021 /$ cr030698+

16. Chidambaram J, Ramkumar R, Rahuman AA, Perumal P. Green synthesis of gold nanoparticles using seed aqueous extract of Abelmoschus esculentus and its antifungal activity. Industrial Crops and Products. 2013;45:423-429. doi: 10.1016/j.indcrop.2012.12.019

17. Chandran SP, Chaudhary M, Pasricha R, Ahmad $A$, Sastry M. Synthesis of gold nanotriangles and silver nanoparticles using Aloevera plant extract. Biotechnology Progress. 2006;22(2):577-583. doi: 10.1021/bp0501423

18. Song JY, Hyeon KJ, Kim BS. Biological synthesis of gold nanoparticles using Magnolia kobus and Diopyros kaki leaf extract. Process Biochemistry. 2009;44(10):11331138. doi: $10.1016 / \mathrm{j}$.procbio.2009.06.005

19. Kaur GJ, Arora DS. In vitro antibacterial activity of three plants belonging to the family Umbelliferae. Inter J Antimicrob Agents. 2008;31(4):393-395. doi: 10.1016/j.ijantimicag.2007.11.007

20. Vitali LA, Beghelli D, Nya PCB, et al. Diverse biological effects of the essential oil from Iranian Trachyspermum ammi. Arab J Chem. 2016;9(6):775-786. doi: 10.1016/j. arabjc.2015.06.002
21. Choudhury S, Ahmed R, Kanjilal PB, LeclecqPA. Composition of the seed oil of Trachyspermum ammi (L.) Sprague from Northeast India. J Essent Oil Res. 1998;10(5):588-590. doi: 10.1080/10412905.1998.9700979

22. Zarshenas MM, Moein M, Samani SM, Petramfar P. An overview on ajwain (Trachyspermum ammi) pharmacological effects; modern and traditional. Journal of Natural Remedies. 2014;14(1):98-105.

23. Haiss W, Thanh NTK, Aveyard J, Fernig DG. Determination of size and concentration of gold nanoparticles from UV-Vis spectra. Anal Chem. 2007;79(11):4215-4221. doi: 10.1021/ac0702084

24. Rauf A, Qaisar M, Uddin G, Akhtar S, Naveed M. Preliminary Phytochemical Screening and Antioxidant Profile of Euphorbia prostrate. Middle-East Journal of Medicinal Plants Research.2012;1(1):09-13. doi: 10.5829/idosi.mejmpr.2011.1.1.1103

25. Uddin G, Rauf A, Siddiqui BS, Muhammad N, Khan A, Shah SU. Anti-nociceptive, antiinflammatory and sedative activities of the extracts and chemical constituents of Diospyrous lotus L. Phytomedicine. 2014;21(7):954-959. doi: 10.1016/j. phymed.2014.03.001

26. Lu F, Gao Y, Huang J, Huang J, Sun D, Li Q. Roles of biomolecules in the biosynthesis of silver nanoparticles: Case of Gardenia jasminoides Extract. Chin J Chem Eng. 2014;22(6):706-712. doi: 10.1016/ S1004-9541(14)60086-0

27. Ibrahim HMM. Green synthesis and characterization of silver nanoparticles using Banana peel extract and their antimicrobial activity against representative microorganisms. J Radiat Res App/ Sci. 2015;8(3):265275. doi: 10.1016/j.jrras.2015.01.007

28. Mistry B. A Handbook of Spectroscopic Data Chemistry: UV, IR, PMR, CNMR and Mass Spectroscopy, Oxford Book Company, Gujrat. 2009.

29. Alfredo VNR, Victor SM, Marco CLA, Rosa GEM, Miguel, CLA, Jesus AAA. Solventless synthesis and optical properties of $\mathrm{Au}$ and $\mathrm{Ag}$ nanoparticles using Camellia sinensis extract. Mater Lett. 2008;62(17-18):31033105. doi: 10.1016/j.matlet.2008.01.138

30. Khan $H$, Saeed M, Muhammad N, Rauf A, Khan AZ, Ullah R. Antioxidant profile of constituents isolated from Polygonatum verticillatum rhizomes. Toxicol Ind Health. 2016;32(1):138-142. doi: $10.1177 / 0748233713498454$

31. Rehman S, Khan H. Advances in antioxidant potential of natural alkaloids. Current Bioactive Compounds. 2017;13(2):101-108. doi: 10.2174/15734072126661 60614075157

32. Uddin G, Rauf A, Siddiqui BS, Khan H, Barkatullah, Ullah R. Antinociceptive, antioxidant and phytochemical studies of Pakistani medicinal plants. Pak J Pharm Sci. 2016;29(3):929-933.

33. Muhammad N, Saeed M, Khan H, Haq I. Evaluation of $n$-hexane extract of Viola betonicifolia for its neuropharmacological properties. I Nat Med. 2013;67(1):1-8. doi: 10.1007/s11418-012-0636-0

34. Asif M, Sultana $S$, Akhtar N. A panoramic view on phytochemical, nutritional, ethanobotanical uses and pharmacological values of Trachyspermum ammi Linn. 
Asian Pac J Trop Biomed. 2014;4(Suppl 2):545-553. doi: 10.12980/APJTB.4.2014APJTB-2014-0242

35. Kudavidanage EP, Dissanayake DMI, Keerthirathna WLRK, Nishshanka NLW, Peiris LDC. Commercial formulation of chlorpyrifos alters neurological behaviors and fertility. Biology (Basel). 2020;9(3):49. doi:10.3390/biology9030049

36. Garcia DA, Bujons J, Vale C, Sunol C. Allosteric positive interaction of thymol with the GABAA receptor in primary cultures of mouse cortical neurons. Neuropharmacol. 2006;50(1):25-35. doi: 10.1016/j. neuropharm.2005.07.009

37. Bentley G, Newton S, Starr J. Studies on nociceptive action of $\alpha$-agonist drugs and their interactions with opioids mechanisms. BrJ Pharmacol. 1983;79(1):125134. doi: 10.1111/j.1476-5381.1983.tb10504.x

38. Duarte ID, Nakamura M, Ferreira S. Participation of the sympathetic system in acetic acid-induced writhing in mice. Braz J Med Biol Res. 1988;21(2):341-343.
39. Khan $H$, Saeed M, Gilani AUH, Khan MA, Dar A, Khan I. The antinociceptive activity of Polygonatum verticillatumrhizomes in pain models. $J$ Ethnopharmacol. 2010;127(2):521-527. doi: 10.1016/j. jep.2009.10.003

40. Ahsan SK, Shah AH, Tanira MO, Ahmad MS, Tariq M, Ageel A M. Studies on some herbal drugs used against kidney stones in Saudi folk medicine. Fitoterapia. 1990;61(5):435-438.

41. Srivastava KC. Extract of a spice-omum (Trachyspermum ammi)- shows antiaggregatory effects and alters arachidonic acid metabolism in human platelets. Prostaglandins Leukot Essent Fatty Acids. 1988;33(1):16. doi: 10.1016/0952-3278(88)90115-9

42. Ratnasooriya WD, Peiris LDC, Jayatunga YNA. Analgesic and sedative action of monocrotophos following oral administration in rats. Medical Science Res. 1995;23(6):403-406. 